\title{
Internacionalização - Navegando por mares desconhecidos
}

Fernanda Goulart Ferrer ${ }^{1}$

${ }^{1}$ Administração de empresas / Escola de Administração de Empresas de São Paulo / FGV (Fundação Getúlio Vargas) 


\title{
INTERNACIONALIZAÇÃO - NAVEGANDO POR MARES DESCONHECIDOS
}

Resumo: Marcos era proprietário de uma pequena empresa, muito inovadora e focada em equipamentos para a área médica e hospitalar, que estava incubada em um Parque Tecnológico. Em um determinado momento, tem um insight de negócio que leva seu produto para um mercado diferente e a empresa a um novo patamar. Agora, dono de uma empresa que vale alguns milhões de reais, ele acredita que se encontra em um novo estágio de expansão inevitável, embora não tenha constatação sobre qual será a melhor opção de investimento para a empresa nos próximos anos. Após reunir-se com a equipe gerencial da empresa, precisa decidir entre realizar ou não a internacionalização da empresa neste momento.

Palavras-chave: Internacionalização. Empreendedorismo. Pequenas empresas.

\section{Introdução}

Organizando os últimos detalhes para a reunião com os gerentes da Organização, que seria no dia seguinte, Marcos parou por um instante e fez uma breve viagem no tempo sobre os desafios vividos nos últimos treze anos. Com uma história de reviravoltas e muitos obstáculos, a Liven necessitava de decisões importantes para os próximos anos.

Saindo do Parque Tecnológico, onde se localizava a empresa, Marcos encontrou sua esposa e compartilhou com ela seus receios:

\begin{abstract}
"Como decidir sobre um investimento financeiro tão grande em um mercado tão desconhecido? Seria a internacionalização a melhor alternativa para a empresa agora? Internacionalizar frente a tantas dúvidas com capital de terceiros e estar à frente de concorrências ou correr o risco de perder mercados e expandir em detrimento de um cenário futuro mais confiante e de mais segurança financeira?"
\end{abstract}

\section{História da empresa}

Marcos construiu sua carreira profissional sempre vinculada à área acadêmica, fez mestrado em engenharia biomédica, desenvolveu sua carreira em pesquisas e em multinacionais focadas em equipamentos e produtos para a área médica e hospitalar, acumulando grande experiência neste mercado.

Como a maioria dos brasileiros, manteve o sonho de empreender, além de continuar a atuar na área em que tinha satisfação pessoal e profissional. Em 2007, após quatro anos de pesquisa na área, fundou a Liven, uma empresa de soluções para a área da saúde, com o propósito de promover bem-estar e qualidade de vida, e, além disso, a empresa tinha como diferencial oferecer um serviço de excelência tecnológica.

A empresa aspirava atender às necessidades de hospitais com um equipamento para auxílio à infusão intravenosa de medicamentos, terapia que requer alto nível de precisão. Diante disso, idealizou o VIAFLUX, equipamento que expressa a exata vazão de soro, em mililitros por hora ou gotas por minuto, com extrema precisão, ajudando os profissionais da área da saúde
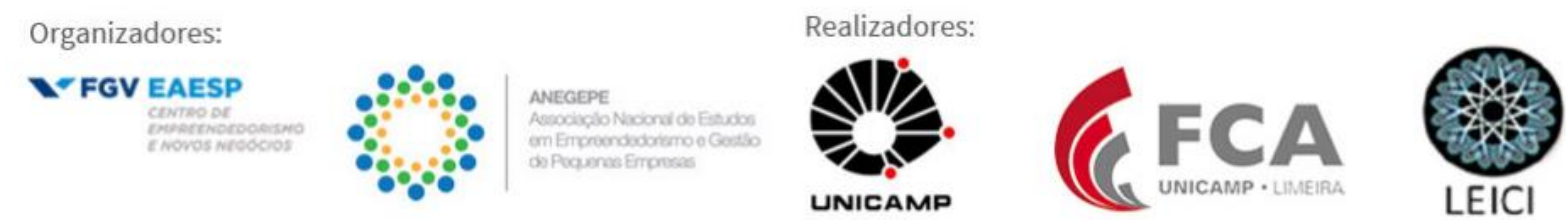
na preparação da terapia intravenosa, proporcionando-lhes maior segurança e confiabilidade no tratamento do paciente.

A Liven estava focada no desenvolvimento de novas tecnologias, concentrando-se principalmente nas operações que agregavam maior valor e que garantiam o conteúdo intelectual do produto.

\section{Os primórdios - Da incubação ao mercado}

Em 2004, Marcos e seus sócios souberam da abertura de um edital de incubação do Parque Tecnológico de São José dos Campos, no Estado de São Paulo, principal incubadora de negócios da Região do Vale do Paraíba. Como estavam iniciando um modelo de negócio com um produto inovador, voltado para a área médica e hospitalar, decidiram participar do processo seletivo.

O processo seletivo durou três meses e foi muito concorrido. Era a primeira vez que Marcos e sua equipe participavam de uma seleção como essa. Entretanto, a Liven conseguiu, e se instalaram na incubadora por um período de três anos. Marcos pensava:

\footnotetext{
"Estar incubado dentro de um Parque Tecnológico foi fundamental para o desenvolvimento e o crescimento da empresa, pois através dela pudemos fortalecer competências em pesquisa, desenvolvimento e gestão, contando com uma infraestrutura própria e focada na criação de sinergia entre os negócios."
}

Na incubadora, puderam contar com uma enorme rede de colaboração, mentorias e um método específico de acompanhamento da evolução do negócio, que era baseado em seis eixos: desenvolvimento do comportamento empreendedor; foco no produto ou serviço; mercado; gestão; estrutura produtiva e capital.

A empresa só se mantinha incubada e, posteriormente, era graduada se apresentasse evolução nos pilares mencionados. Após serem graduados pela incubadora de negócios do Parque Tecnológico de São José dos Campos, se tornaram residentes do Centro Empresarial do mesmo Parque, pois não queriam sair deste ambiente propício à inovação.

A incubadora foi um ambiente próspero ao desenvolvimento do negócio. A instituição ajudou tanto no desenvolvimento do produto quanto na gestão da pequena empresa como um todo. Outra vantagem foi a aproximação da Liven de outras empresas e parceiros estratégicos, o que lhe favoreceu, inclusive, a obter subvenção econômica da PIPE (Pesquisa Inovativa em Pequenas Empresas), oferecida pela FAPESP (Fundação de Amparo à Pesquisa do Estado de São Paulo), no valor de $\mathrm{R} \$ 200.000,00$. Este dinheiro foi aplicado para averiguar a viabilidade técnica e econômica do produto logo no início.

Para desenvolver o negócio, o empreendedor participou de diversos workshops e capacitações do SEBRAE (Serviço Brasileiro de Apoio às Micro e Pequenas Empresas), um parceiro fundamental nessa estruturação inicial, bem como o IPT (Institutos de Pesquisas Tecnológicas) e outras instituições parceiras do Parque Tecnológico de São José dos Campos.

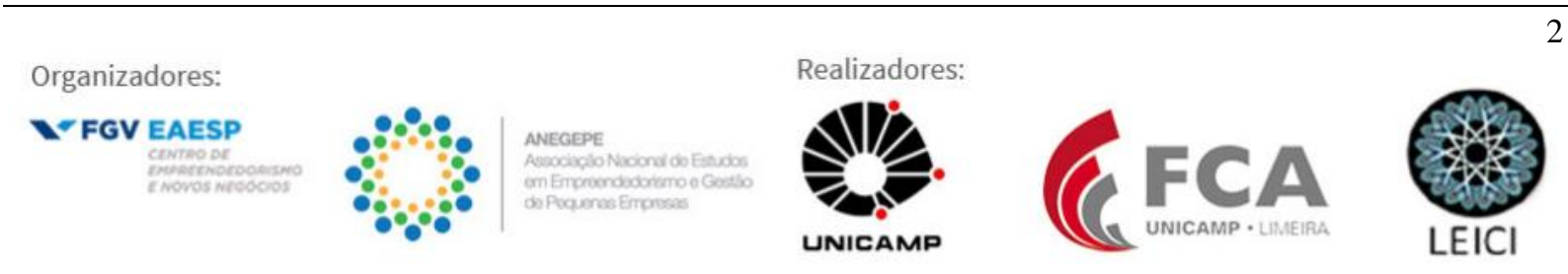




\section{O Insight do negócio}

O produto já estava sendo desenvolvido há quatro anos e, mesmo tendo sido totalmente finalizado para comercialização, ainda havia uma pendência que se arrastava: a certificação do produto pela ANVISA e por outras instituições reguladoras da área de saúde ainda estava em processo de decisão.

Sem as certificações, a empresa não poderia realizar a venda e adentrar ao mercado, deixando Marcos decepcionado e de mãos atadas. Os recursos da empresa estavam exaurindo, o tempo de incubação se aproximava do fim e a data da certificação era uma incógnita.

Foi em um café informal nos corredores da incubadora que um colega, e vizinho empreendedor de outra empresa incubada, mencionou que sua esposa era veterinária e questionou se o produto que Marcos estava desenvolvendo teria aplicação na área animal. Este foi um momento divisor de águas na vida de Marcos e de sua empresa. Focado em um determinado segmento, ele não havia vislumbrado um outro mercado promissor para seu negócio. Marcos considerou:

“O Mercado PET vinha ganhando desenvoltura nos últimos anos e não exigia as regulamentações que atravancavam o deslanchar de meu negócio. Eureca, a ideia é perfeita!"

\section{Mudando o alvo}

Após o Insight de Marcos, seu core business havia mudado da área médica para a veterinária. Apesar de ser leigo no setor animal, a saída parecia uma válvula de escape para todos os seus problemas. Além da menor burocracia, o que facilitava a entrada no segmento, este mercado estava em franca expansão no Brasil e no mundo.

O pequeno negócio de Marcos começou a explorar o mercado veterinário com muito sucesso, estabeleceu-se e atingiu seu break-even point, inclusive sustentando a área médicohospitalar até a obtenção da certificação da ANVISA e demais órgãos competentes.

Vindo de um mercado exclusivo, em 2007 já tinha quase $50 \%$ do seu faturamento advindo das vendas para o mercado pet, e, em 2016, este percentual beirava os $70 \%$, muito maior que a área médica comum. O mercado da empresa abrange todo o Brasil, mas tem maiores vendas na região Sudeste e Sul do país, representando $80 \%$ da carteira de clientes.

\section{Portfólio de Produtos Liven}

O produto inicial desenvolvido pela empresa de Marcos foi o VIAFLUX, equipamento que expressa a vazão de soro com extrema precisão, em mililitros por hora ou gotas por minuto, ajudando os profissionais da área da saúde na preparação da terapia intravenosa. Hoje, seu portfólio conta com mais de 42 produtos, tais como: monitores multiparamétricos, oxímetros, eletrocardiogramas, focos, lasers, anestesias e ventiladores pulmonares.

Em 2017, com 70\% do faturamento da empresa derivado dos produtos voltados ao mercado veterinário, o que inicialmente surgiu apenas como uma alternativa chave para aquele momento acabou se tornando o principal fator de sucesso da empresa.

\section{Organizadores:}

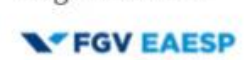

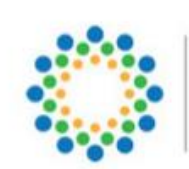

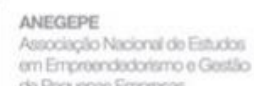
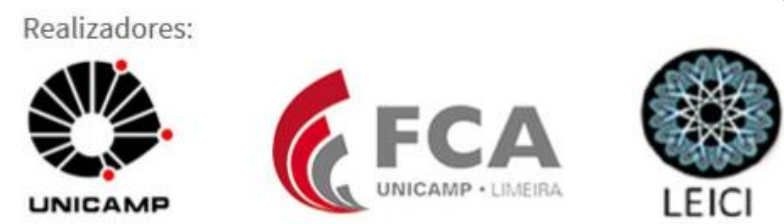
A situação da Liven financeiramente é positiva, a lucratividade já havia crescido sobremaneira de 2006 a 2017. Marcos consegue dispor de uma quantia maior que um milhão de reais por ano em pesquisas, trabalhando com desenvolvimento de pesquisas em inovação, voltadas a novos equipamentos de uso médico/veterinário.

Um dos objetivos da empresa é, cada vez mais, elaborar meios inovadores para a saúde humana e animal, auxiliando médicos, enfermeiros e veterinários. Para isso, acredita que seja fundamental a satisfação do cliente, inovação, excelência no atendimento, abertura a ações de melhoria, segurança e qualidade.

\section{O Setor Médico Hospitalar Brasileiro}

Entende-se por Health Devices o setor de produtos para saúde, contemplando os segmentos Odontológico, Laboratorial, Radiológico, Equipamentos médico-hospitalares, Implantes e Materiais de consumo (como hipodérmicos, têxteis, adesivos e outros). O mercado de atuação da Liven é especificamente o de Health Devices para o setor médico hospitalar.

De acordo com a Brazilian Health Devices, projeto executado pela Associação Brasileira da Indústria de Artigos e Equipamentos Médicos e Odontológicos (ABIMO) em parceria com a Apex-Brasil, a indústria de equipamentos médicos em 2016 era capaz de suprir $90 \%$ da demanda do mercado interno e exportar para mais de 180 países, gerando mais de 60 mil empregos no Brasil.

A produção nacional desse segmento cresceu cerca de $72 \%$ de 2007 até 2013, mostrando ser um excelente segmento industrial, com organizações suficientemente competentes para conquistar cada vez mais mercado.

Estima-se que o Brasil movimenta um mercado de $\mathrm{R} \$ 8$ bilhões nesta área, que ainda está em expansão, gerando cada vez mais emprego e surgimento de novas empresas, assim, acirrando a concorrência. Este setor abrange empresas que produzem desde pequenos equipamentos a tomógrafos complexos, com a capacidade de suprir $95 \%$ da demanda de um hospital inteiro.

\section{Um pouco do mercado Pet no Brasil e no mundo}

Mais do que companheiros fiéis, os pets são vistos e tratados hoje como membros da família. Essa relação cada vez mais próxima e humanizada movimenta o mercado de negócios especializados, que se diversifica em relação a produtos e serviços e torna-se mais rentável e profissionalizado. Os consumidores deste nicho se encontram tanto nas classes A quanto B e C. Alguns dados referentes aos hábitos de consumo dos donos de animais de estimação são apresentados na tabela abaixo: 
Tabela 1 - Informações e números do Mercado Pet no Brasil

\begin{tabular}{|c|}
\hline Informações e número do Mercado Pet no Brasil em 2017 \\
\hline $\begin{array}{c}50 \% \text { dos donos de cães dizem ter relação de pai e filho com o animal, o que explica o investimento em saúde } \\
\text { animal. }\end{array}$ \\
\hline Donos de cães investem, em média, 300 reais por mês para a manutenção de seu animal. \\
\hline Donos de gatos gastam por volta de 120 reais, em média, nos cuidados de seus felinos. \\
\hline Sete em cada dez cães ficam dentro de casa e $43 \%$ destes cães dorme na cama de seus tutores. \\
\hline $\begin{array}{c}\text { do\% dos veterinários percebem que os tutores estão mais atentos aos avanços da medicina veterinária e à saúde } \\
\text { de sets }\end{array}$ \\
\hline
\end{tabular}

Fonte: Abinpet 2017

Segundo dados revelados pelo IBGE (Instituto Brasileiro de Geografia e Estatística) em 2016, havia mais de 50 milhões de cães e 22 milhões de gatos de estimação no Brasil. Dados revelados pela ABINPET (Associação Brasileira da Indústria de Produtos para Animais de Estimação) apontam um mercado de 19,2 bilhões de reais e expansão de quase $7 \%$ em relação ao ano de 2015. Embora sofra com os reflexos da desaceleração da economia, o setor resistiu à crise e surpreende pela resiliência diante dos indicadores de desemprego e corrosão da renda pela inflação.

O mercado de animais de estimação corresponde a 0,38\% do PIB (Produto Interno Bruto) nacional, índice superior ao da linha branca de geladeiras e fogões.

A grande vertente deste segmento é a saúde animal que representa quase o dobro da fatia do mercado Pet geral, dado interessante considerando o core business da Liven. Impulsionado pelo grande avanço da tecnologia, o setor teve o crescimento de $13 \%$ em 2016 em relação a 2015, segundo a ABINPET.

Umas das explicações para este destaque todo é a mudança do comportamento das pessoas em relação aos seus animais. Nos últimos tempos, os animais de estimação passaram para dentro de suas casas e ganharam o título de membros da família.

O Brasil é o terceiro colocado no ranking do mercado mundial do setor, com 5,3\% do faturamento global, atrás de Estados Unidos, país responsável por $42 \%$ de todo o mercado mundial e do Reino Unido, com 6,7\%. Em 2016, o setor faturou 103,7 bilhões de dólares, alta de $1,5 \%$ sobre o ano anterior. Para 2017 , a projeção é que o setor cresça $6,6 \%$.

\section{Caminhos para internacionalização}

De acordo com a Apex-Brasil, Agência Brasileira de Promoção de Exportações e Investimentos, somente no ano de 2017, entre os meses de janeiro a julho, as exportações da indústria Pet nacional movimentaram 119,62 milhões de dólares, tendo o Paraguai como líder nas importações com 19,3 milhões de dólares, seguido por Hong Kong, Uruguai, Estados Unidos e Chile.

A entrada em novos mercados e ampliação do market share, bem como o fortalecimento da marca da empresa, novos desafios e ganhos de experiência e elevação da empresa a um novo Patamar são pontos considerados quando se pensa em internacionalizar a empresa.
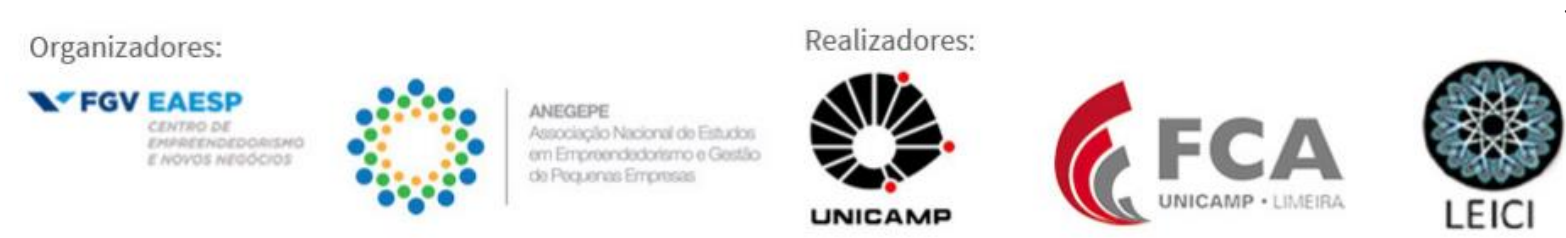
No entanto, quando se pensa em exportação, por exemplo, imediatamente surgem alguns obstáculos: excesso de burocracia, sistema tributário, infraestrutura de transporte, taxa de câmbio, barreiras tarifárias, financiamento para exportação, adequações de produtos e processos produtivos para atender possíveis clientes, falta de informações de potencias mercados, escala de produção e trabalhadores qualificados.

Todavia, dentre todas as dificuldades elencadas acima, as que mais impactam negócio de Marcos, na opção pela exportação, seriam: a escala de produção, financiamento para exportação e adequações de produtos e processos produtivos.

Dentre os aspectos citados, a adequação de produtos e processos produtivos é o mais complexo, pois isso pode variar em cada país, com suas agências e órgãos reguladores próprios, podendo aumentar os custos de investimento para obtenção das certificações exigidas e também ampliar o dead line do projeto de internacionalização.

Outra preocupação pertinente do empreendedor era a escala de produção. Quantos produtos devem ser exportados para compensar os riscos e todo o trâmite? Será que a empresa tem capacidade produtiva para atender o mercado interno e fornecer para o exterior? O ciclo operacional e o ciclo financeiro são capazes de suprir esta investida no exterior?

E o financiamento para esta estratégia de expansão? Há algumas linhas de financiamento derivadas dos programas governamentais e vinculadas ao Desenvolve - SP e ao BNDES (Banco Nacional de Desenvolvimento Econômico e Social) que são muito mais atrativas que qualquer outra linha de financiamento advinda de bancos comerciais. Mas será esta é a melhor saída? O investimento para as ações da empresa viria certamente de algum dos órgãos citados, pois Marcos não dispõe de valores financeiros para expansão em tamanha escala e para as adequações necessárias.

\section{Desafios da Liven para o futuro}

Inspirado após uma boa noite de sono, Marcos começa a reunião fazendo um breve briefing do atual cenário da empresa e seus questionamentos futuros. Os gerentes apresentam números de faturamento, representatividade de vendas dos produtos e dados do mercado mundial do setor. Marcos esperava que seus gerentes dessem um parecer a respeito dos seus questionamentos para auxiliá-lo a posicionar a Liven em um patamar mais próspero para os próximos anos.

Deveria Marcos investir no planejamento para a internacionalização? Focaria em algum mercado específico? Dentre as alternativas de internacionalização, a exportação seria a melhor delas? Senão, qual seria o outro formato? O investimento em regiões brasileiras e em pesquisa e inovação tecnológica não seria mais promissor? Estaria Marcos perdendo tempo com uma oportunidade excelente?
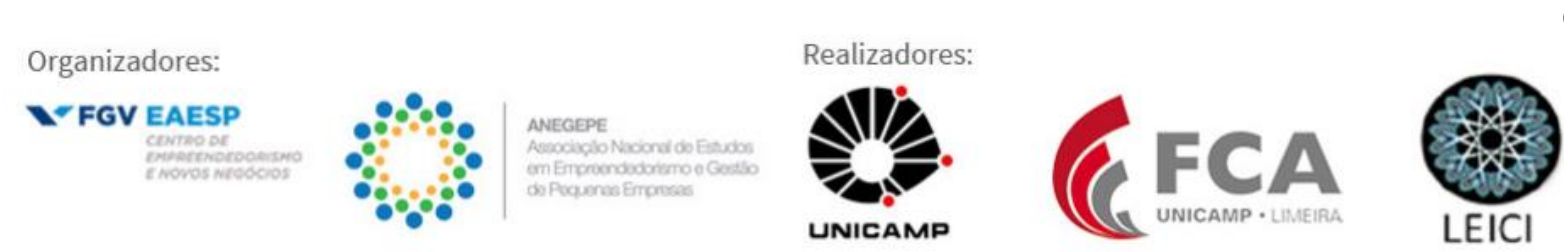


\section{Anexo 1 - O produto inicial - VIAFLUX}

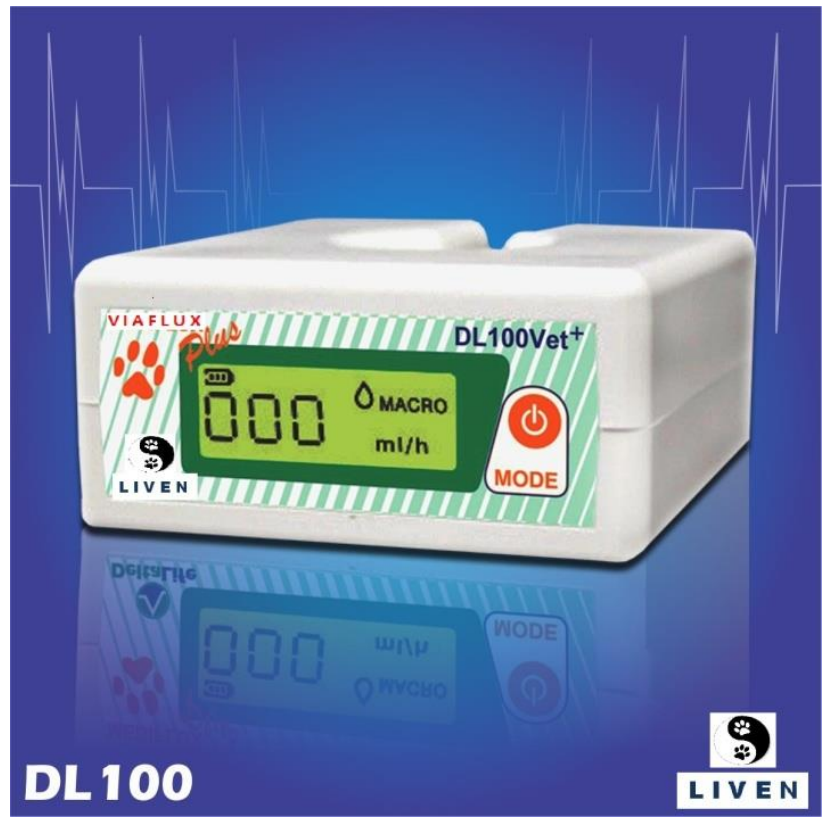

Fonte: Cedida pela empresa

\section{Características:}

- Auxilia o profissional veterinário na regulagem da vazão do medicamento na infusoterapia aplicada, diminuindo o tempo e aumentando a precisão, expressando a correta vazão do medicamento em gotas por minuto ou ml por hora;

- Reduz o desperdício de medicamentos;

- Melhora significativamente o tratamento;

- Aumenta a segurança, reduz complicações causadas por super ou sub dosagem;

- Reduz o tempo de procedimento no ajuste da vazão;

- Se adequa à maioria dos equipamentos no mercado, tanto micro quanto macro gotas;

- Alarme a interrupção de fluxo. 
Anexo 2 - Exportação Brasileira do mercado Pet

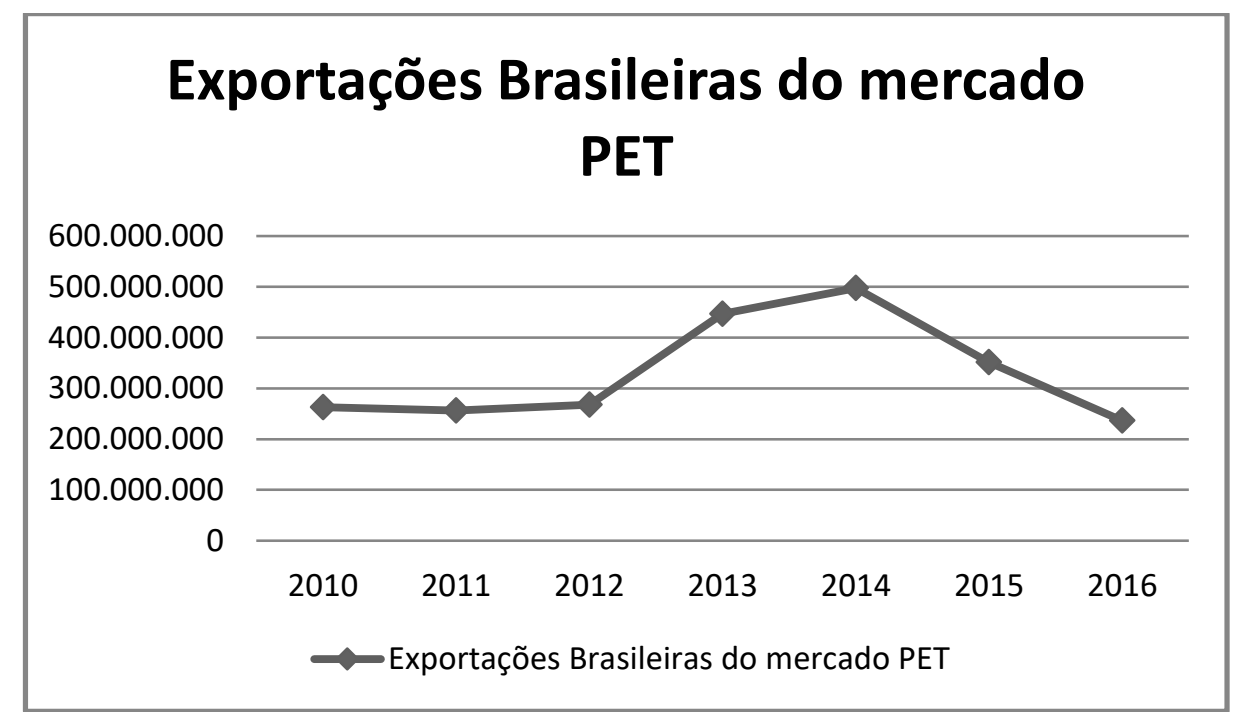

Fonte: Abinpet 2017

Anexo 3 - Exportação da indústria PET brasileira de janeiro a julho de 2017.

\begin{tabular}{|c|c|}
\hline Destino & $\begin{array}{c}\text { Valor exportado total em } \\
\text { milhões (US\$ FOB) }\end{array}$ \\
\hline Paraguai & $\mathbf{1 9 , 6}$ \\
\hline Hong Kong & $\mathbf{1 6 , 0}$ \\
\hline Uruguai & $\mathbf{1 0 , 8}$ \\
\hline Estados Unidos & $\mathbf{8 , 8}$ \\
\hline Chile & $\mathbf{7 , 8}$ \\
\hline Colômbia & $\mathbf{7 , 2}$ \\
\hline Argentina & $\mathbf{6 , 5}$ \\
\hline Nigéria & $\mathbf{6 , 0}$ \\
\hline Bolívia & $\mathbf{4 , 0}$ \\
\hline Alemanha & $\mathbf{2 , 5}$ \\
\hline
\end{tabular}

Fonte: Abinpet 2017 
Anexo 4 - Mercado Pet no Brasil

Crescimento do Mercado PET 2016/2015

\begin{tabular}{|c|c|}
\hline \multicolumn{2}{|c|}{ Crescimento do Mercado PET 2016/2015 } \\
\hline Pet Vet (Medicamentos Veterinários) & $\mathbf{6 , 7 \%}$ \\
\hline Pet Care (Equipamentos, Higine e Beleza) & $\mathbf{5 , 5 \%}$ \\
\hline Pet Food (Alimentos) & $\mathbf{4 , 9 \%}$ \\
\hline
\end{tabular}

Fonte: Abinpet 2017

Anexo 5 - Faturamento Mercado PET no Brasil em 2016

\section{Faturamento Mercado Pet 2016}

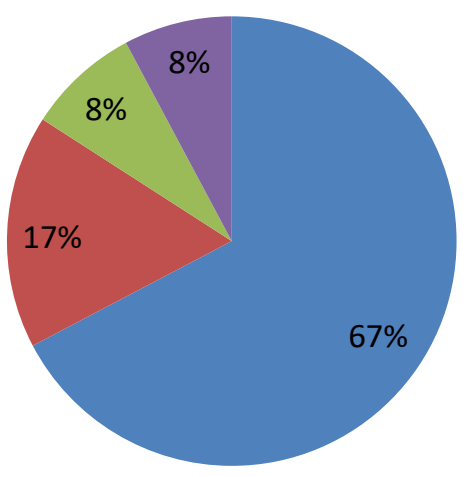

Pet Food

- Pet Serv

Pet Care

Pet Vet

Fonte: Abinpet - 2017 
Anexo 6 - Mercado mundial do setor Pet

\begin{tabular}{|r|r|r|}
\hline \multicolumn{1}{|c|}{ Faturamento Mercado Pet Mundial 2016} \\
\\
\\
\hline
\end{tabular}

Fonte: Abinpet 2017 


\section{Notas de Ensino}

O caso de Marcos, proprietário de uma pequena empresa de equipamentos para área médica, hospitalar e veterinária, descreve um dilema quanto à internacionalização da empresa, onde ele necessita decidir:

a) Realiza internacionalização da empresa e investe esforços para este propósito (e, neste caso, para qual mercado e de que maneira a internacionaliza);

b) Dedica-se aos mercados internos e abre mão da ideia, correndo o risco de perder um mercado cujo seu produto ainda é inovador.

\section{Utilização recomendada e objetivos de aprendizagem}

Este caso foi desenvolvido para ser aplicado nas seguintes disciplinas: gestão de negócios; estratégia empresarial; estratégia internacional da empresa; estratégia e processo organizacional e comércio exterior.

Os objetivos deste caso são:

- Oportunizar discussões iniciais sobre as vantagens da internacionalização e dificuldades inerentes ao processo;

- Reconhecer motivações e as estratégias de internacionalização das empresas;

- Discutir o papel do líder da empresa na exploração de oportunidades de mercado e a dinâmica de decisão;

- Discutir especificidades do comércio exterior.

\section{Aporte teórico para a discussão do caso}

As sugestões a seguir compreendem aspectos essenciais na discussão sobre a internacionalização da empresa, no entanto, os professores podem realizar alterações na utilização das referências sugeridas por tratar-se de um tema amplo e em virtude da delimitação que dará à discussão.

A abertura da temática pode trilhar uma breve contextualização histórica sobre a evolução da internacionalização em empresas brasileiras, podendo usar como base a reunião de trabalhos em "Expansão internacional das empresas brasileiras" (Rocha, 2007).

A partir da compreensão de que os motivos para internacionalizar refletem nas escolhas das estratégias de internacionalização, a contribuição de Wright (2000) pode favorecer a elucidação sobre os formatos de exportação e suas vantagens e desvantagens.

Ainda com relação às estratégias de internacionalização, os artigos de Hitt et al. (2008) e Vasconcellos et al. (2006) podem contribuir com leituras sobre aspectos positivos da administração estratégica em decorrência da escolha pela internacionalização.

Sobre as barreiras e vantagens do processo de internacionalização, ainda, podemos utilizar como fonte também Certo e Peter (2005), trazendo uma perspectiva sobre a análise do ambiente internacional como fundamental para formular a estratégia da empresa e também sobre a questão cultural, que deve ser considerada na tomada desta decisão. Certo e Peter (2005) trazem a dimensão cultural e individual sobre as implicações que a mudança pode ocasionar na vida 
das pessoas da organização com a internacionalização, perspectiva fundamental às vezes renegada neste tipo de decisão, o que ocasiona conseqüências prejudiciais.

Em seguida, algumas teorias que se destacaram podem ser apresentadas para pensar por que, o que, quando, onde e como as empresas internacionalizam. Uma delas seria a teoria do Paradigma Eclético (Dunning, 1980, 1981, 1998), onde os alunos poderiam refletir sobre as diferentes motivações das empresas ao internacionalizarem e se localizarem nesses países e suas vantagens, segundo o autor, de propriedade, da internalização e de localização.

Outra teoria que se destaca na literatura e pode ser apresentada é a Teoria da Escola de Uppsala (Johanon \& Vahlne, 1977). Os autores demonstraram neste "modelo de Uppsala", segundo (Mariotto, 2007) os estágios seqüenciais do processo de internacionalização, e, focam no desenvolvimento do comprometimento com o mercado externo a partir do conhecimento sobre o mesmo. Com isso, os alunos podem aprender sobre uma forma de internacionalização gradativa que permite identificação de riscos e oportunidades de maneira ascendente.

Por fim, artigos relacionados às políticas públicas de incentivo à exportação e seus reflexos nas pequenas empresas podem ser abordados para entender esta historicidade da internacionalização no Brasil e a importância do apoio governamental, com os artigos de Santos (2015) e Rosa (2007).

\section{Dinâmica para discussão do caso}

Para aplicação do caso é dado como sugestão o passo a passo abaixo, sendo importante que os alunos leiam com antecedência a teoria subjacente ao tema e o caso de ensino.

O objetivo é que o aluno possa se colocar em posição de decisor para ter uma real dimensão das diversas implicações que a internacionalização pode promover na realidade das organizações.

Sugestão de aplicação:

Etapa 1 (10 minutos): Dividir a turma igualmente, recebendo metade da turma o questionário A e metade o questionário B para ser respondido individualmente, conforme segue:

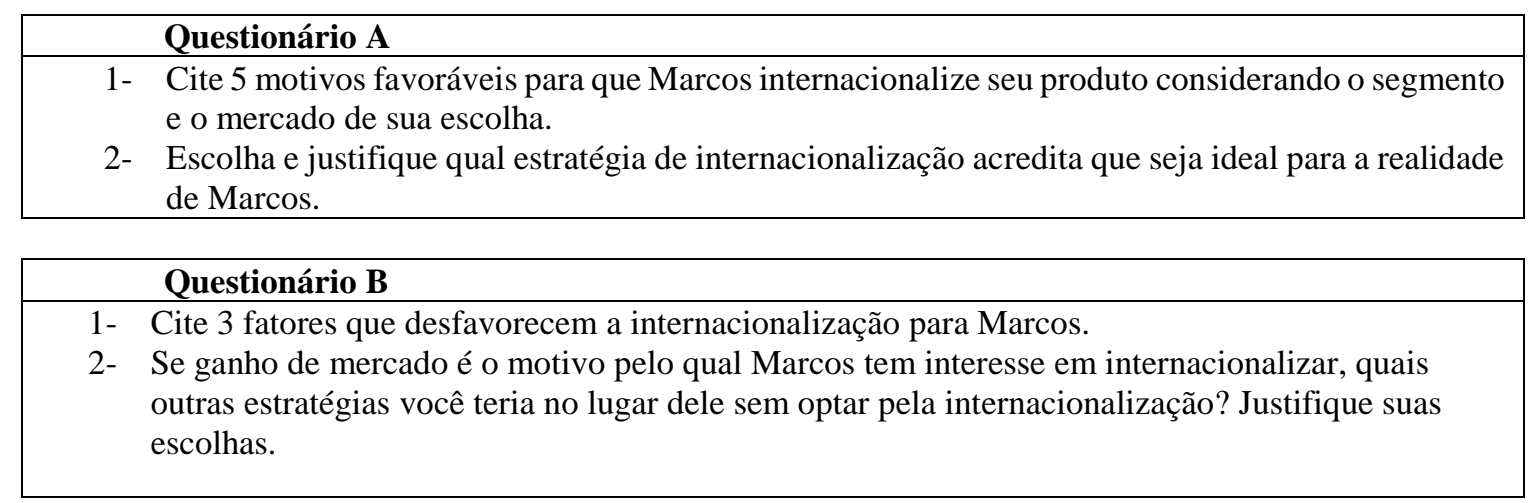


Etapa 2 (15 minutos): Forme 2 grupos grandes de alunos, ou divida-os em número maior de grupos caso a turma seja muito grande, de forma que todos os grupos tenham pessoas que receberam tanto o questionário A quanto B. Em seguida, por sorteio, entregue para os grupo o papel "a favor da internacionalização" e "contra a internacionalização neste momento". Os grupos terão 15 minutos para se preparar para um debate.

Etapa 3 (25 minutos): Realização de um debate. Como em uma assembleia, os participantes terão que defender seu ponto de vista e justificar a posição que lhe foi posta. $\mathrm{O}$ papel do professor é interceder de forma a trazer os dados do caso, mediar o grupo sempre que necessário e promover a discussão da teoria trabalhada no curso. 


\section{Referências}

Abinpet. (2017). Associação Brasileira da Indústria de Produtos para Animais de Estimação. Faturamento 2016 do Setor Pet aumenta 4,9\% e fecha em R \$18,9 bilhões. Disponível em: $<$ http://abinpet.org.br/site/faturamento-2016-do-setor-pet-aumenta-49-e-fecha-em-r-189bilhoes-revela-abinpet/>. Acessado em 10.out.2017.

Certo, C. S., \& Peter, J. P. (2005). Administração Estratégica: Planejamento e Implementação da Estratégia. São Paulo, SP: Pearson Education do Brasil.

Dunning, J. H. (1980). Toward an eclectic theory of international production: some empirical tests. Journal of International Business Studies, v.11, n.1, pp.9-31.

Dunning, J. H. (1981). The international production and multinational enterprise. Londres: George Allen and Unwin.

Dunning, J. H. (1998). Explaining international production. Londres: George Allen and Unwin.

Hitt, M. A., Ireland, R. D. \& Hoskisson, R. E.. Administração Estratégica: Competitividade e Globalização. 7. ed. São Paulo: Cengage.

Johanson, J. \& Vahlne, J. E. (1977). The Internationalization Process of the Firm - A Model of Knowledge Development and Increasing Foreign Market Commitments. Journal of International Business Studies. Vol. 8, n.1, pp 23-32.

Mariotto, F. L. (2007). Estratégia Internacional da Empresa. Thompson.

Rocha, A. da et al. (2007). Expansão internacional das empresas brasileiras: revisão e síntese. In: Fleury, A; Fleury, M. T. (Org.). Internacionalização e os países emergentes. São Paulo: Atlas.

Rosa, P. R.; Rhoden, M. I. dos S..(2007). Internacionalização de uma empresa brasileira: Um estudo de caso. XXXI Encontro do ANPAD. Disponível em:〈http://www.anpad.org.br/admin/pdf/APS-B2208.pdf>. Acessado em 09.out.2017.

Santos, L. B.. (2015). Políticas públicas e internacionalização de empresas brasileiras. Soc. nat., Uberlândia, v.27, n.1, p.37-52,2015. Disponível em <http://www.scielo.br/scielo.php? script=sci_arttext\&pid=S1982-45132015000100037\&lng=en\&nrm=iso > . Acessado em 09.ou t.2017.

Vasconcellos, M. A. S., Lima, M. \& Silber, D. S.(Org.). (2006). Gestão de Negócio Internacionais. São Paulo: Saraiva. 
Wright, P., Kroll, M. J., \& Parnell, J.. (2000) Administração estratégica: Conceitos. São Paulo: Atlas S.A.. 